\title{
CONTEXTO, TENDENCIAS Y ACTORES DE LA RECONCEPTUALIZACIÓN*
}

\section{CONTEX, TRENDS AND ACTORS OF RECONCEPTUALIZATION}

Sergio Quintero-LONDOÑO**

\section{Resumen}

Objetivo. Este artículo intenta demostrar las mediaciones entre el desarrollo sociohistórico del modo de producción capitalista y el trabajo social, entendido como una profesión inscrita en la división sociotécnica del trabajo. Metodología. De manera particular, se analiza la crisis estructural del capital en las décadas 1960 y 1970, así como los actores y fuerzas profesionales que protagonizaron la Reconceptualización delTrabajo Social. Resultados. A partir de un análisis histórico de orden cualitativo, fundamentado en análisis documental, se identifica la Reconceptualización como un movimiento que hace parte de la renovación profesional, en la que se encuentran tendencias teórico-políticas diferenciadas. Conclusión. Finalmente, llamando la atención sobre el carácter 'politicista' del marxismo que inspiró la Reconceptualización, se sugiere un abordaje riguroso de la obra madura de Marx, la crítica de la economía política.

Palabras clave: capitalismo, crisis estructural, Reconceptualización, marxismo.

\begin{abstract}
Objective. This article attempts to demonstrate the mediations between the socio-historical development of the capitalist ways of production and social work understood as a profession inscribed in the socio-technical division of labor and production. Methodology. The structural crisis of capital in the 1960s and 1970s is particularly analyzed, as well as the actors and professional forces that led the reconceptualization of social work. Results. From a historical analysis of a qualitative nature based on documentary analysis, reconceptualization is identified as a movement that is part of professional renewal, in which differentiated theoretical-political tendencies are found. Conclusion. Finally, drawing attention to the "politicist" character of Marxism that inspired reconceptualization, a rigorous approach to Marx's mature work, the critique of political economy, is suggested.
\end{abstract}

Key words: capitalism, structural crisis, reconceptualization, marxism.

\footnotetext{
* El presente artículo es una versión ampliada y revisada de la ponencia "El movimiento profesional latinoamericano de los años 60-70 y sus posibles impactos para Colombia”, presentada en el XIV Congreso Colombiano de Trabajo Social realizado en 2013 en Bogotá. Constituye resultados parciales de los estudios de maestría y doctorado realizados entre 2012 y 2018 en la Universidad Federal de Río de Janeiro y la Universidad del Estado de Rio de Janeiro.

** Universidad de Caldas. Manizales, Colombia. E-mail: seranquilog@hotmail.com

(1) orcid.org/0000-0001-9232-7083 Google Scholar
} 
Contexto, tendencias y actores de la Reconceptualización

\section{Introducción}

La comprensión del trabajo social como una profesión inscrita en la división socio-técnica del trabajo es una premisa que, inspirada en la tradición marxista, posibilita el abordaje de la historia profesional y sus mediaciones con las contradicciones socio-políticas y económicas del modo de producción capitalista (Iamamoto y Carvalho, 1984).

A partir de esta perspectiva de análisis, se puede entender el carácter contradictorio de la profesión como consecuencia objetiva de las contradicciones de la sociedad en la que se desempeña, rompiendo así cualquier determinismo endógeno y auto-referencial que ha caracterizado la interpretación histórica del trabajo social en América Latina y, particularmente, en Colombia.

En el presente texto se aborda la crisis del capital, proceso contradictorio que, constituido por condiciones objetivas y subjetivas, se expresa en las 'esferas' más amplias y abstractas del modo de producción (en su ley o metabolismo), y en instituciones y relaciones más específicas, llegando incluso hasta la vida cotidiana.

Pretendemos demostrar cómo la crisis mundial capitalista de los años 60 y 70 del siglo XX adquirió determinadas características en el contexto latinoamericano, manifestándose en diferentes instancias, entre las que optamos por resaltar algunos rasgos que condujeron a la renovación del trabajo social, particularmente a la Reconceptualización.

De acuerdo con los argumentos introductorios que presentamos a continuación, será posible observar cómo los periodos de crisis del capital, al presentar rebatimientos en diferentes niveles sociopolíticos y económicos, brinda las posibilidades y exigencias para transformaciones profesionales, tal y como sucedió con el movimiento de la Reconceptualización.

\section{Discusión}

\section{Los “años gloriosos” y la crisis del capital}

Posterior a la segunda Guerra Mundial (1939-1945) la sociedad capitalista se reestructuró a nivel global, generando condiciones mucho más favorables al capitalismo monopolista (hegemonizado desde Europa Occidental y Estados Unidos). Con un poder preponderante, los Estados Unidos de Norteamérica asumieron gran parte de control político-económico y cultural, definiendo la jerarquía política, económica y militar a nivel planetario (Harvey, 2013; Mandel, 1985). 
Al plantear como principal objetivo el "desarrollo económico", las fuerzas hegemónicas de la sociedad impusieron diversas medidas de ajuste, estableciendo la premisa ideológica de que los países del "capitalismo periférico" deberían seguir los caminos indicados por el capital monopolista y los nuevos instrumentos de regulación (Banco Mundial, BM; Fondo Monetario Internacional, FMI; Organización de las Naciones Unidas, ONU; Organización de Estados Americanos, OEA; Organización del Tratado del Atlántico Norte, OTAN; Banco Interamericano de Desarrollo, BID) ${ }^{1}$.

El patrón de producción fordista-taylorista, conocido como de producción rígida, garantizó la dinámica del mercado al crear en tiempo récord grandes cantidades de mercancía, acelerando la circulación del capital y la reproducción del orden social. La imposición del tiempo de producción de parte de las máquinas hacia los trabajadores (control del trabajo muerto sobre el trabajo vivo), alcanzado a través de diversas técnicas (como la banda transportadora), hacen que se aumenten exponencialmente los niveles de producción y valorización.

Los niveles de producción, hasta entonces inéditos, brindan la posibilidad de crecimiento exponencial del capital, al tiempo que se ofrecen algunas garantías favorables para la reproducción de la fuerza de trabajo. Estas condiciones son las que permiten denominar este periodo histórico (1945-1973) como las tres décadas doradas del imperialismo, enmarcadas en lo que Mandel (1985) retomó como “ondas largas con tonalidad creciente”.

Aunque de forma diferenciada, tornándose más clara la experiencia europea que la norteamericana, se configura el llamado "Estado de Bienestar", a través del cual el Estado garantiza su intervención de manera directa en determinados sectores de la economía capitalista $^{2}$. En este nuevo contexto de intervención estatal se atiende la cuestión social a través de la asistencia y políticas sociales, al tiempo que se interviene de manera directa en la economía de mercado, fortaleciendo el gran capital; es decir, por un lado se garantiza la reproducción de la fuerza de trabajo (clase trabajadora) y, por otro, se amplía la posibilidad de producción-reproducción de valor.

Las propias condiciones sobre las que se configura el Estado de Bienestar permiten que cada clase y fracción de clase social alcance parte de sus objetivos, es así que durante la década de 1960 se fortalecieron diversos tipos de organizaciones que poco a poco iban conquistando

\footnotetext{
${ }^{1}$ La implementación de tales medidas supuestamente garantizaría el equilibrio del mercado y las necesidades sociales, posibilitando su incorporación en el mercado mundial, sin embargo, ninguna de las medidas adoptadas por los países del capitalismo dependiente para alcanzar los niveles de "desarrollo económico" arrojaron los resultados esperados; por el contrario, en la medida que los países 'subdesarrollados' seguían las orientaciones del capital monopolista, más se arraigaban como economías dependientes. ${ }^{2}$ En Navarro (1997), desde una posición liberal se encuentra un análisis que evidencia el distanciamiento entre el proyecto de bienestar estadounidense (New Deal) y el de algunos países de la Unión Europea (Welfare State). Por su parte en Gough (1982), desde una perspectiva marxista se presenta una exposición competente frente al carácter contradictorio del Estado de Bienestar y las políticas sociales.
} 
derechos políticos, económicos y sociales. Partidos políticos de izquierda y sindicatos obreros (además de los denominados "nuevos movimientos sociales") obtuvieron conquistas concretas y avanzaron en la representación directa ante diferentes instancias gubernamentales, desde donde intentan incidir en la toma de decisiones de la política económica y social.

Ahora bien, si durante algún tiempo el capital logra controlar y beneficiarse de conquistas garantizadas por la lucha de los trabajadores, en un momento determinado tales exigencias sobrepasan los límites preestablecidos por el capital, lo que genera un choque que sólo se resuelve a través de la lucha de fuerzas antagónicas.

De la misma forma que durante los años 40 se había establecido la hegemonía monopolista a nivel mundial, a finales de los años 1960 e inicios de 1970, se presenta la crisis estructural del capital $^{3}$.

Durante el periodo de crisis se manifiestaron contradicciones de orden político, económico y cultural que se encontraban estrechamente relacionadas unas con las otras, y que no es posible entender de manera aislada dado que hacen parte de una totalidad concreta. Ahora bien, para un mejor análisis, de manera abstracta se abordan en su autonomía relativa.

Las principales contradicciones de orden económico traen como consecuencia directa el ataque al "Estado de Bienestar", especialmente a las políticas sociales. Con la caída del keynesianismo se generó un proceso de restauración conservadora en el que se combatían directamente los derechos ciudadanos, precarizando las condiciones de vida de las clases subalternas. La mayoría de las conquistas laborales alcanzadas por las clases trabajadoras son revertidas a través de la contra-reforma del Estado, que tiene como principal objetivo la instauración del neoliberalismo ${ }^{4}$.

La crisis económica de la década de1970 se manifiesta de diversas formas, entre las que resalta la Guerra de Vietnam, la crisis del petróleo de 1973 y la pérdida de hegemonía del patrón dólar-oro con la caída del Acuerdo de Bretton Woods; sin embargo, estos tres vectores (que suelen ser presentados como las causas de la crisis) encuentran su origen en la auto-negación del valor con el aumento de la composición orgánica del capital, y la consecuente tendencia decreciente de la tasa de ganancia.

\footnotetext{
${ }^{3}$ Itsván Mèszáros (2013) caracteriza la crisis capitalista de los años 70 como una crisis estructural. La imposibilidad de pagar la deuda y de cubrir el déficit del Estado capitalista, la posibilidad del descalabro económico producto del estallido de las burbujas financieras, las nulas condiciones de ampliar mercados, el desempleo estructural, el deterioro ambiental del planeta, la guerra imperialista, entre otras, son contradicciones sin salida que enfrenta el capitalismo y que caracterizan su crisis, ya no como una cuestión 'coyuntural' (cíclica), sino como una condición estructural.

${ }^{4}$ Las experiencias desarrolladas por Margaret Thatcher en Inglaterra y Ronald Reagan en los Estados Unidos son las más representativas en el "capitalismo central”. Por su parte, la dictadura chilena (1973-1990) constituye un ícono experimental del neoliberalismo para la región latinoamericana.
} 
Las causas fundamentales de la crisis obedecen a la tercera revolución tecnológica de mediados del siglo XX (Mandel, 1985) puesto que esta permite el aumento de la productividad del capital con menos fuerza de trabajo (capital variable), aumentando el ejército industrial de reserva (desempleo) y la consecuente caída en los salarios (aumentando el costo de vida). Así se encuentran todas las condiciones para un aumento de la riqueza material (valores de uso) a través del desarrollo de las fuerzas productivas, y una disminución en la valorización del valor; este contexto responde al metabolismo del capital y constituye una crisis inminente. A su vez, en el campo político emergen diversas expresiones políticas de la crisis que guardan estrecha relación con las alteraciones en el modo de producción.

En Asia la mayor expresión de la crisis (tanto en términos políticos como económicos) se presentó en Vietnam. La ofensiva anticomunista desatada por los Estados Unidos conllevó a una guerra sin cuartel (1955-1975), que concluyó con el triunfo y la autodeterminación vietnamita. Además de la derrota militar, los Estados Unidos de Norteamérica sufrió un fuerte golpe en su economía, puesto que la inversión en la guerra había generado la necesidad del endeudamiento económico, que se desdobla en el recorte de políticas sociales y derechos, tanto en los Estados Unidos como en los países dependientes (Mèszáros, 2013) ${ }^{5}$.

La guerra de Vietnam (y de toda Indochina) estimuló el sentimiento solidario de diferentes sectores sociales a nivel mundial; es así que en Europa, el creciente movimiento juvenil, estudiantil y obrero encontró uno de los puntos de unidad para expresar sus contradicciones en contra del imperialismo. En "el viejo mundo" tanto la lucha de los trabajadores como de los movimientos de contracultura (hippies, ambientalistas, feministas, culturales, etc.) desataron manifestaciones de protesta que alcanzan mayor expresión en el "Mayo Francés", las protestas inglesas, la caída del Franquismo en España, y en la Revolución de los Claveles en Portugal, con la que se facilitaron los procesos de liberación nacional en África.

La independencia de países africanos representó la mayor expresión política de la crisis en este continente. Congo (1960), Angola (1975), Mozambique (1975) (y otros) no solo alcanzaron la independencia política de países europeos, sino que además expresaban afinidades con la política internacional de la Unión Soviética ${ }^{6}$.

Por su parte, en los Estados Unidos se abre un ciclo de protestas lideradas por el movimiento negro e inmigrantes latinos, cuestionando la discriminación social y el racismo, al tiempo que se pone en el centro del debate la lógica de la sociedad capitalista-imperialista. Las protestas en contra de la Guerra de Vietnam congregaron diversas expresiones de solidaridad, particularmente de jóvenes y estudiantes.

\footnotetext{
${ }^{5}$ Metafóricamente Mèszáros dice que la Guerra de Vietnam fue paga con tarjeta de crédito.

${ }^{6}$ Con los países africanos que alcanzan su independencia, pero no se articulan a las directrices de Estados Unidos y la Unión Soviética, se crea el denominado "Tercer Mundo".
} 
En América Latina el ciclo de crisis se abre con el triunfo de la Revolución Cubana (1959) a través de la cual se demostró la posibilidad del triunfo político por medio de la guerra de guerrillas. La instauración de un gobierno revolucionario estimuló el surgimiento de diversas organizaciones insurgentes en la mayoría de los países latinoamericanos. Por su parte, en Chile con la llegada al gobierno de la Unidad Popular (1970-1973) se vivió una experiencia donde explícitamente se proyectó "abrir caminos hacia el socialismo" a través de las herramientas legales brindadas por la “democracia liberal”. Posteriormente Nicaragua (1979) avanzó en un proceso revolucionario en el que se combinó la lucha insurreccional y las herramientas de participación legal ${ }^{7}$.

Aunque en diferentes proporciones, en todos los países de América Latina se presentó gran influencia de la renovación católica posterior al Concilio Vaticano II y la Conferencia Episcopal de Medellín (1968), adquiriendo gran relevancia la Teología de la Liberación.

Con la crisis política y económica del capital, lo que queda en evidencia es la necesidad inaplazable de diseñar nuevos planes de desarrollo, sea para la reproducción ampliada del capital, o para buscar alternativas de ruptura que tengan como horizonte la superación del mismo. Las formas de gobernar, así como las políticas económicas son reestructuradas, con lo cual se vivencian claras modificaciones en la manera de atender la cuestión social ${ }^{8}$.

Los debates y críticas surgidas dentro de partidos y movimientos políticos se transfieren a instituciones (como las universidades) y organizaciones (como las juveniles y estudiantiles), presentando formas singulares de renovación.

\section{La Reconceptualización como expresión del auge y crisis capitalista}

Existe un consenso evidente en el reconocimiento de la Reconceptualización como movimiento fuertemente 'influenciado' o determinado por el contexto político de crisis que se vivió tanto a nivel mundial como latinoamericano durante las décadas de 1960 y 1970.

El análisis de las transformaciones sociopolíticas y económicas muestra su carácter determinante sobre el movimiento profesional. Más allá de sus particularidades internas, la Reconceptualización se caracterizó por el enfrentamiento entre diferentes perspectivas teórico-políticas que encontraban su raíz más profunda en proyectos societarios tensionados en la contradicción capital-trabajo? .

\footnotetext{
${ }^{7}$ Un análisis introductorio sobre estas experiencias se encuentra en Sader (1992).

${ }^{8}$ Ante la imposibilidad de restablecer el control a través del orden legal, en América Latina el capital monopolista y sus clases aliadas recurrieron a las alternativas más violentas de gobiernos autocráticos. Las dictaduras de Brasil (1964), Uruguay y Chile (1973) y Argentina (1976) tal vez son las más representativas de la estrategia del gran capital para mantenerse en el poder, e instalar el neoliberalismo.

${ }^{9}$ Netto (2012) plantea que la Reconceptualización en Latinoamérica fue posible gracias al desarrollo de tres vectores fundamentales: a) la crisis de las ciencias sociales (positivistas), b) la renovación de la Iglesia Católica, y c) las luchas del movimiento estudiantil.
} 
Para una mayor comprensión del proceso histórico, se abordarán de manera introductoria los Congresos Panamericanos de Servicio Social y los Seminarios Regionales Latinoamericanos de Trabajo Social (ambos determinados por el contexto sociopolítico), entendiendo que en la dinámica de estos eventos se generó el proceso de renovación en el que se inscribe la Reconceptualización.

Dos características fundamentales surgen en trabajo social como consecuencia de las transformaciones sociales. Primero, el carácter conservador, sustentado en el funcionalestructuralismo, en el moralismo católico y la intervención caritativa ya no se presentan como único fundamento posible, pues se muestra incapaz de responder a los nuevos retos de la sociedad de la posguerra; y segundo, se genera un abanico de posibilidades y alternativas teórico-políticas más cualificadas y competentes que pretenden responder al nuevo contexto latinoamericano. En otras palabras, el viejo trabajo social se torna insuficiente y a cambio emergen diversas perspectivas que inauguran un ciclo de pluralidad y divergencia.

Ya en el Movimiento de Reconceptualización propiamente dicho se evidencian tensiones y transformaciones inherentes a todo proceso histórico. Al decir de Iamamoto (2003),

\begin{abstract}
A pesar de haber sido gestado en medio de la política desarrollista y de haber sido tributario de sus parámetros analíticos, el movimiento de Reconceptualización a partir de la década de 70 se encuentra fuertemente marcado por la presencia de análisis y propuestas profesionales con nítida inspiración marxista, creando una brecha con sus propias producciones iniciales. (p. 229)
\end{abstract}

\title{
Los Congresos Panamericanos de Servicio Social
}

Es necesario entender que buena parte de las transformaciones en la práctica profesional se hacen necesarias en los años 1950 para atender las nuevas demandas de la realidad social, puesto que las viejas herramientas y métodos no son suficientes para satisfacer los intereses de los empleadores, de los usuarios y mucho menos para la comprensión objetiva del movimiento de la realidad. Estas transformaciones, al ser una necesidad objetiva, son estimuladas tanto por sectores conservadores (clásicos o modernos) y por críticos.

Los Congresos Panamericanos de Servicio Social (1945-1971) fueron financiados inicialmente por la Organización de las Naciones Unidas (ONU) y, posteriormente, por la Organización de Estados Americanos (OEA), manteniendo un cuadro direccional con objetivos claros que apuntaban a la doctrina desarrollista de la II posguerra. 
En las conclusiones del primer Congreso (Santiago, Chile, 1945), reconociendo "las más importantes obligaciones del mundo de la posguerra", y las acciones que frente al nuevo contexto puede ejercer la ONU, se 'recomendó':

Que los delegados del Primer Congreso Panamericano de Servicio Social, al regresar a sus respectivos países, recalquen y traigan la atención de los representantes oficiales de sus países en el Consejo Económico y Social de la Organización de las Naciones Unidas, la urgente necesidad que hay de crear una organización para el bienestar social (...). (AnderEgg y Kruse, 1984, p. 55-56)

En el marco del II Congreso (Río de Janeiro, Brasil, 1949) se continúo con la influencia norteamericana tanto en las temáticas abordadas como en su tratamiento. Al finalizar el II Congreso, los organizadores y participantes del evento solicitaron a la OEA que designara la sede del III Congreso; el cual, posteriormente, tuvo lugar en San Juan, Puerto Rico en 1957.

En esta oportunidad (Puerto Rico, 1957) se profundizaron los argumentos en favor del desarrollo; además se defendió de manera explícita el carácter neutral y apolítico del servicio social latinoamericano. Así lo registran las memorias del congreso:

\begin{abstract}
Que los trabajadores sociales se preocupen más por conocer y establecer relación con los organismos de trabajadores y patronos, como un medio de comprender mejor los alcances del problema laboral y de poder, en su oportunidad, ofrecer una colaboración constructiva para el establecimiento de unas mejores relaciones obrero-patrono. (AnderEgg y Kruse, 1984, p. 82) ${ }^{10}$
\end{abstract}

En el IV congreso (San José, Costa Rica, 1961) se presentaron algunos debates cuestionadores del servicio social tradicional, y de las directrices dadas por organismos internacionales encargados de difundir el desarrollismo. En las conclusiones, consideraciones y recomendaciones se expresaba la necesidad de fortalecer el carácter investigativo, la comprensión del sistema socioeconómico de cada país y el aporte en los procesos de cambio equilibrado. De este modo, aunque no se dejaron de aplicar las directrices de la ONU o la OEA, se intentó resaltar algunas particularidades de la intervención profesional en cada país. La tensión se hizo presente, aunque permaneció la hegemonía tradicional.

No se puede plantear que en este Congreso se haya presentado una ruptura con la "ideología imperialista”; por el contrario, se estaba atendiendo a la estrategia norteamericana trazada a

\footnotetext{
${ }^{10}$ Aquí se evidencia la influencia del pensamiento católico inspirado por la Encíclica Papal Quadragesimo Anno. Un estudio sobre la influencia católica en la profesión se encuentra en Manrique (1982).
} 
través de la Alianza para el Progreso, al elogiar "el papel central de la educación en cualquier programa de desarrollo nacional y la importancia que le han conferido los gobiernos americanos según el acuerdo de Punta del Este” (Ander-Egg y Kruse, 1984, p. 90).

La síntesis de los Congresos anteriores y el esclarecimiento definitivo en cuanto a su ideal desarrollista se presentó en Lima (Perú) en 1965 con el V Congreso. El tema central fue El Bienestar Social y el Proceso de Desarrollo de los Países de América, el cual fue abordado a través de 3 sub-ejes: I El Desarrollo; II El factor humano en el proceso de desarrollo, y III El Servicio Social y el Desarrollo.

En 1968 se realizó el VI Congreso en Caracas (Venezuela). En este momento, las condiciones de la crisis capitalista y el clima político revolucionario que rodeaba a toda Latinoamérica se empezó a expresar en el trabajo social. En este Congreso se encontró la máxima expresión de contradicción entre lo 'nuevo' y lo 'viejo', ratificando algunos elementos desarrollistas, pero también, reivindicando formas alternativas de desarrollo regional, al margen de 'imperialismo'.

Veamos algunas expresiones a considerar como elementos modernizantes y críticos. Los documentos del Congreso expresan: "Que los centros de formación en Servicio Social deben asumir responsabilidad en el proceso de adecuación de los planes y programas de estudio a la concepción de desarrollo" (Ander-Egg y Kruse, 1984, p. 124). En esta misma dirección, reconociendo el valor que tiene la planificación en el desarrollo, argumenta: "La planificación, considerada como técnica en sí misma, es un proceso racional que puede ser utilizado para fines de distinto contenido. Tiene un carácter instrumental operativo y es por tanto neutra." (Ander-Egg y Kruse, 1984, p. 115).

Ahora bien, también se hacen evidentes expresiones críticas que generan una contradicción que apunta hacia una ruptura de orden político:

La importancia de modelos de desarrollo, elaborados sin tomar en cuenta la realidad latinoamericana, lejos de ser benéfico para orientarnos hacia metas de desarrollo realistas y alcanzables, se convierten en un nuevo obstáculo, dado lo inapropiado que resulta su aplicación. (Ander-Egg y Kruse, 1984, p. 113)

Y continúa más adelante:

Las actividades del profesional de trabajo social han estado marcadas por la atención de los problemas individuales o colectivos que se derivan de las patologías sociales, sin tomar en cuenta que tales desajustes son generados en gran parte por la inadecuación de las estructuras sociales. (Ander-Egg y Kruse, 1984, p. 119) 
En el último Congreso realizado (Quito, Ecuador, 1971), que sólo se logra llevar a cabo hasta la mitad de la agenda, tenía como línea orientadora el desarrollismo, pero ya se había difundido lo suficiente la perspectiva de la teoría de la dependencia, en la que se argumenta que el subdesarrollo de los países periféricos constituye la consecuencia lógica del desarrollo de los países centrales; estos argumentos serán acompañados por algunas expresiones de la teología de la liberación. Bajo esta condición, las contradicciones en los debates se agudizan.

A partir de este momento se pretendían implementar análisis sobre la realidad latinoamericana que tomaban distancia de los lineamientos políticos de los Congresos anteriores ${ }^{11}$.

Producto de la pérdida de hegemonía de las fuerzas conservadoras y la avanzada de las diversas corrientes críticas, el Congreso es sometido a un cierre inesperado respondiendo a las políticas del presidente ecuatoriano José María Velasco Ibarra, quien permitió a las tropas militares ocupar el Palacio Legislativo de Quito, lugar que había sido destinado para las discusiones académicas. A partir de entonces fueron suspendidos los congresos panamericanos.

El análisis de los congresos puede permitir el siguiente planteamiento: surgen bajo el control y al servicio de los Estados Unidos de Norteamérica y sus doctrinas ideológicas; para el cumplimiento de esta tarea utiliza (entre otras) como principal herramienta el discurso del desarrollo; sin embargo, en la medida que las condiciones socio-políticas del continente se iban transformando (planteando una fuerte crítica al 'imperialismo'), el contenido de los congresos se fue transformando hasta salirse del control y directriz hegemónica; el desarrollo, que había sido identificado como la alternativa posible y deseable, termina siendo objeto de críticas. En medio de la confrontación, por orientación de las instancias sociales y profesionales conservadoras, se elimina el espacio de discusión que había perdurado por dos décadas y media.

\section{Los Seminarios Regionales Latinoamericanos de Servicio Social}

Los Seminarios surgieron como consecuencia de los esfuerzos de profesionales de diferentes países (especialmente del Cono Sur) que se caracterizaron por intentar darle (lo que ellos llamaron) un carácter "verdaderamente latinoamericano" a las discusiones del trabajo social de la región. Una de las ideas fundamentales era la consolidación de teorías y métodos propios del servicio social latinoamericano, que respondiera a las condiciones y necesidades de los países del sur' ${ }^{12}$.

\footnotetext{
${ }^{11}$ Una de las grandes sorpresas fue la elección de los cuatro vicepresidentes del Congreso, dado que "los candidatos oficiales" (históricamente delegados de los sectores más conservadores, afines a la ONU y la OEA) no fueron elegidos por la asamblea, y por el contrario, resultaron electos aquellos participantes que se identificaban con los planteamientos críticos que empiezan a generar tensión con el conservadurismo profesional, e inclusive con el desarrollismo.

${ }^{12}$ Aquí se encuentra el origen del debate profesión-disciplina y la supuesta especificidad del trabajo social.
} 
Al igual que los Congresos Panamericanos, frente a los Seminarios Latinoamericanos es necesario tener en cuenta el periodo histórico en el cual se desarrollaron, 1965-1972, puesto que es en este marco temporal cuando surgen y se fortalecen diversos procesos políticos organizativos en casi todo el territorio latinoamericano, protagonizando la crisis del capital y la "lucha antiimperialista".

En las conferencias centrales del I Seminario (Porto Alegre, Brasil, 1965) se encuentra el discurso del compromiso sociopolítico de los profesionales, la necesidad de reivindicar derechos de los sectores más vulnerables, y de atender las necesidades propias de Latinoamérica. Si bien se mantiene una perspectiva próxima al desarrollismo, ya se identifica la relación dependiente del capitalismo central y periférico.

En este Congreso hubo participación de Jorge Furtado, Maria Lúcia Carvalho da Silva y José Lucena Dantas, entre otros. Una de las expresiones de Carvalho en el Seminario sintetiza bien la tendencia hegemónica:

El Servicio Social debe esforzarse por "filtrar" y sustraerse de las influencias europeas y norteamericanas que tan marcadamente ha sufrido y que han dificultado un auténtico crecimiento y enriquecimiento. Debe tender, asimismo, a superar la tendencia a imitar o a repetir las experiencias extranjeras, descubriendo nuevas soluciones y procurando respuestas de cuño más nacionalistas. (Ander-Egg, Cassineri, Fernández, Parisi y Barreix, 1975, p. 404)

En el II seminario (Montevideo, Uruguay, 1966) liderado por Herman Kruse se encontraban planteamientos más críticos, donde emergieron posturas que pretendían superar la doctrina desarrollista. Tres ejes temáticos posibilitaron la discusión: 1. Problemas metodológicos del Servicio Social, 2. Servicio Social. Evolución y Revolución, y 3. Política del Servicio Social en el Desarrollo. En el segundo eje se presentaba la influencia de los sectores más avanzados presentando las siguientes ponencias: El Servicio Social en los países capitalistas; El Servicio Social en los países socialistas; Nuevas orientaciones en la formación de asistentes sociales; a su vez, en el tercer eje se presentaba la ponencia que representa el espíritu del seminario: El Servicio Social como agente de cambio.

Según Ander-Egg, durante este Seminario, "Cornely (Seno) aborda temas hasta ese entonces tabú: la conveniencia de la militancia política de los asistentes sociales, y la incorporación a organismos sindicales a fin de actuar como grupos de presión” (Ander-Egg et al., 1975, p. 408).

El III Seminario (General Roca, Argentina, 1967) “Servicio Social y Educación” fue coordinado por Natalio Kisnerman. En el marco de este Seminario se hizo énfasis en evaluar las condiciones 
Contexto, tendencias y actores de la Reconceptualización

vividas en América Latina. Algunas preguntas orientadoras del debate fueron: ¿Qué clase de servicio social se necesita en América Latina y cuál tendría que ser el papel del asistente social?

En el IV Seminario (Concepción, Chile, 1969) se encuentra una de las más explícitas referencias a lo que fue el movimiento de la Reconceptualización. Los acercamientos al marxismo fueron parte integrante de las discusiones tanto en los conferencistas centrales como en los participantes; también fueron centro del debate los planteamientos de Paulo Freire, quien para la época ya contaba con amplio reconocimiento en algunos países de la región.

Entre ejes y conferencias centrales se encuentra el siguiente contenido: Alienación y praxis del Servicio Social (eje); alienación de los profesionales de Servicio Social en los contextos en transición de América Latina; Marxismo y Servicio Social; La rebelión de los jóvenes y Servicio Social; La revolución latinoamericana y el Servicio Social (conferencias centrales).

En el marco del debate se identifica la necesidad de,

Iniciar el proceso de Reconceptualización del Servicio Social, que debe comprender los presupuestos filosóficos y científicos del quehacer profesional y, muy especialmente, los aspectos metodológicos, que ya no responden a las exigencias de nuestra sociedad en cambio. (...) Los llamados "métodos básicos" del Servicio Social, son sólo técnicas fragmentarias que minimizan en sus contenidos el campo profesional de esta disciplina. (Ander-Egg et al., 1975, p. 414-415)

También toma fuerza el mesianismo profesional:

El Servicio Social debe promover la formación de una conciencia crítica en los grupos marginales que, por su número y su situación de postergación real, representan una de las fuerzas más dinámicas para impulsar un proceso de auténtica transformación de las estructuras sociales. (...) Todo quehacer humano está respaldado por una ideología (...). Las opciones ideológicas alternativas que se plantean a los profesionales del Servicio Social Latinoamericano tienen una limitación: no pueden ser contrarias al Cambio Social. (Ander-Egg et al., 1975, p. 418)

En el V Seminario (Cochabamba, Bolivia, 1970) se mantuvo la centralidad de la Reconceptualización. A la participación regular de Argentina, Brasil, Chile y Uruguay, se suma la de representantes de Perú, Paraguay y Bolivia, fortaleciendo la legitimidad del evento. 
El tema central de discusión fue la Reconceptualización del Servicio Social a nivel de agencias y organismos con programas de Bienestar Social, desarrollado a través de 3 ejes sub-temáticos, 1. Diagnóstico de la Realidad Latinoamericana; 2. Lo que se entiende por Reconceptualización del Servicio Social; 3. La política de la Agencia, su naturaleza y sus relaciones con el cambio.

Entre los planteamientos más significativos se encuentra,

El compromiso del Servicio Social Latinoamericano consiste en la IDENTIFICACIÓN TOTAL CON LAS CLASES OPRIMIDAS. Para lograr este compromiso es necesario salir del puritanismo, vencer el temor e ingresar en una lucha real que colocará indudablemente al Trabajador Social en el plano político. (Ander-Egg et al., 1975, p. 422)

Finalmente y entrando en un movimiento de retroceso, se realiza el VI seminario en Porto Alegre (Brasil, 1972). De acuerdo con un análisis de las delegaciones de habla hispana y del Grupo ECRO, el evento tenía dos opciones: 1. Responder a la identidad que había caracterizado todo el proceso desde 1965, es decir, aportando al proceso de renovación crítica; o por el contrario, 2. Realizar un evento determinado por las condiciones del país anfitrión bajo la dictadura cívico-militar para re-implementar el carácter 'tecnocrático'. El análisis de sus resultados demuestra que se optó por la segunda opción, impulsando la formación 'tecnocrática', discutiendo de manera preferencial sobre procedimientos, términos y esquemas de la intervención positivista ${ }^{13}$.

El Seminario eliminó de su agenda los análisis de las condiciones sociopolíticas de América Latina, la necesidad de crítica a las condiciones impuestas por el capitalismo, el aporte en el proceso de Reconceptualización y las prácticas emancipadoras de los profesionales; entre otros temas que habían constituido todo el proceso de renovación crítica.

De esta manera, se entra en la recta final de los seminarios regionales latinoamericanos de servicio social, que habían reunido fundamentalmente a los países del Cono Sur; y pese a que las expectativas estaban puestas para retomar el camino cuestionador y 'transformador', que desde Porto Alegre hasta Cochabamba se había encargado de dar una "nueva identidad" al trabajo social, la no realización del siguiente Seminario en Uruguay, cerraron las posibilidades de continuidad en la renovación crítica.

\footnotetext{
${ }^{13}$ También a estos principios corresponden los seminarios de Araxá y Teresópolis. Para un abordaje sobre las características de la Dictadura en Brasil y las particularidades del trabajo social, ver Netto (2012).
} 
Contexto, tendencias y actores de la Reconceptualización

\section{Principales actores de la Reconceptualización}

La forma en que se consolidó la Reconceptualización en cada país es variada, aunque es posible identificar elementos y actores transversales al proceso continental.

Se conoce como Generación del 65 al grupo de profesionales que a partir de 1965 protagonizaron debates que enfrentaban el carácter conservador de trabajo social tradicional, así como la hegemonía 'imperialista' de Estados Unidos.

La Generación 65 es portadora de nuevos debates (fundamentalmente inspirados en el desarrollismo y posteriormente en la teoría de la dependencia) que lograron impulsar un primer momento en la renovación profesional. A lo largo de los seminarios regionales latinoamericanos de trabajo Social (Brasil - 1965, Uruguay -1966, Argentina - 1967, Chile 1969, Bolivia - 1970 y Brasil -1972), se destaca un grupo profesionales del Cono Sur, entre los que se encuentran Herman Kruse, René Dupont, Ricardo Hill, Natalio Kisnerman, Luis María Früm, Juan Barreix, Ezequiel Ander-Egg, Seno Cornely, entre otros ${ }^{14}$.

La participación de estos autores en los seminarios orientaron polémicas que iban desde lo ideológico hasta lo técnico-instrumental, poniendo gran énfasis en la crítica a los "métodos clásicos", la neutralidad valorativa, el imperialismo, los fundamentos católicos conservadores, entre otros.

Del interior de la Generación del 65 surge el Grupo ECRO, compuesto fundamentalmente por profesionales argentinos ${ }^{15}$.

La difusión del pensamiento de la Generación 65 y del Grupo ECRO se realiza por diversos canales, pero se destaca el papel desempeñado por las revistas Selecciones de Servicio Social (de la editorial HVMANITAS) y Hoy en el Servicio Social (de la editorial ECRO). Norberto Alayón y Juan Barreix, autores reconocidos a nivel latinoamericano fueron copropietarios/co-directores de la editorial ECRO, con lo cual tuvieron gran facilidad para difundir su pensamiento.

A pesar de que la editora ECRO no tenía una filiación o articulación a movimientos o fuerzas de inspiración marxista, en el ejercicio plural de divulgar el debate profesional (nueva característica profesional creada por la Reconceptualización), ésta y otras tendencias teóricopolíticas fueron difundidas.

\footnotetext{
${ }^{14}$ Llama la atención que los protagonistas de la Generación 65 en su gran mayoría son hombres, siendo el trabajo social una profesión mayoritariamente integrada por mujeres.

${ }^{15}$ El Grupo ECRO (Esquema Conceptual Referencial y Operativo), se inspira en el psicoanálisis, aunque incorpora elementos críticos de otras áreas y corrientes teóricas.
} 
Ante la tendencia a "importar" y a "traducir" material bibliográfico de otros países, el Grupo ECRO desde el primer momento rehusó la importación y/o traducción (excepto, lógicamente, la de otros países latinoamericanos); en una segunda etapa sus libros comenzaron a ser exportados a países extracontinentales y en el momento actual-como tercera etapa- tiene en trámite contratos de traducción de algunos de sus libros a otros idiomas (alemán, inglés y francés, más concretamente). (Ander-Egg et al., 1975, p. 433)

Constituida como una entidad de mayor alcance, integrando Centroamérica y la Región Andina, se crea la Asociación Latinoamericana de Escuelas de Servicio Social (ALAESS) ${ }^{16}$.

ALAESS surgió en 1965, sin embargo, la idea de un organismo latinoamericano de servicio social se venía discutiendo en eventos de carácter regional. Una vez se concreta la idea de la Asociación Latinoamericana, se empiezan a desarrollar diversas actividades. Los debates profesionales a través de seminarios, foros y congresos fueron el eje central de ALAESS.

Bajo la dirección de ALAESS se llevaron a cabo los seminarios en los que se buscaba una articulación entre teoría y práctica. Aunque inicialmente en estos seminarios no hubo expresiones 'radicales', a partir de 1971 se presentó una mayor intensidad en los debates y orientaciones político-ideológicos. Como consecuencia del ingreso de profesionales más jóvenes y críticos, se vivenció un proceso de 'refundación' de la asociación en el marco del Seminario de Ambato (1971). Con la incorporación al cuerpo directivo de personas más críticas y afines al marxismo, la renovación crítica adquiere mayor relevancia ${ }^{17}$.

Una vez 'refundada' ALAESS, y con las nuevas características introducidas en el Seminario de Ambato, se avanzó en la creación del Centro Latinoamericano de Trabajo Social (CELATS) que tiene como objetivo

Crear una instancia donde se desarrollan: investigaciones docencia, programas de acción, documentación, comunicación, que tiendan a dar una implementación científica en una línea teórica, metodológica y

\footnotetext{
${ }^{16}$ Un hecho que llama la atención es que ALAESS tiene su génesis y desarrollo a lado de las recomendaciones de entes internacionales como la International Association of Schools of Social Work (IASSW) y de profesionales de los Estados Unidos como el caso de Caroline Ware, quien figuró en varias juntas Directivas como Asesora. Posteriormente ALAESS tendría financiación de la democracia cristiana de Alemania Federal a través del Instituto de Solidaridad Internacional (ISI) y la Fundación Konrad Adenauer. Como consecuencia de los debates reconceptualizadores, ALAESS pasa a denominarse ALAETS, cambiando la denominación de Servicio Social por Trabajo Social.

${ }^{17}$ Vale la pena mencionar la influencia de los sectores marxistas o próximos al marxismo, donde se reconoce un liderazgo evidente de Leila Lima Santos, y otros profesionales como Marilda Iamamoto, Consuelo Quiroga, Ana Quiroga, Vicente de Paula Faleiros, Manuel Manrique, Alejandrino Maguiña, Juan Mojica, José Paulo Netto y otros. Para un abordaje introductorio sobre el debate 'refundador' de ALAESS, ver Resumen y Conclusiones del Seminario Latinoamericano para Profesionales en Trabajo Social 1971.
} 
técnica a las tareas que el Trabajo Social debe desarrollar en la realidad latinoamericana, para que este sea un verdadero aporte a la dinámica de transformación. (Mojica y Quiroga, 1975, párr. 11)

El CELATS, con sede en Lima - Perú, se creó bajo una estructura interna compuesta por el Consejo Directivo y el Comité Ejecutivo, además de contar con cuatro áreas programáticas: *Acción de proyectos concretos, **Investigación, ***Capacitación, **** Documentación y comunicación. Por medio de estas áreas se desarrollan proyectos que responden a las condiciones del contexto latinoamericano; investiga sobre condiciones obreras, indígenas y campesinas de la región; capacita y actualiza a los profesionales con el debate de la renovación profesional; impulsa la posgraduación con la primera maestría de trabajo social en la región; y adelanta acciones de documentación y comunicación desde y para Latinoamérica.

Además de la divulgación de varias investigaciones publicadas en los Cuadernos CELATS, y de publicaciones conjuntas con la editora ECRO, en la que se aborda de manera crítica el contexto sociopolítico y el trabajo social, la publicación de la Revista Acción Crítica genera un gran aporte a la Reconceptualización, convirtiéndose en el principal canal de debate y difusión de la región.

Las acciones adelantadas por estos organismos (Generación 65, Grupo ECRO, ALAESS, CELATS) entre otros, configuran una fuerza cuestionadora (con diferencias entre sí) que al enfrentarse al tradicionalismo profesional crean una renovación profesional y da forma al movimiento de la Reconceptualización.

\section{Tendencias y consecuencias de la Reconceptualización}

Según Netto (2012), en la renovación del trabajo social se presentó el enfrentamiento de diversas tendencias ${ }^{18}$; por un lado se encuentran aquellas que de manera explícita pretenden reinstalar las medidas conservadoras que reproducen el orden del capital y los "métodos clásicos"; por otro lado se encuentran quienes reconociendo las transformaciones sociales, políticas y económicas del capital, proyectan algunas medidas modernizadoras de corte desarrollista, que no rompen con la dinámica del capital; y también se encuentran posiciones más radicales que hacen explícita su inspiración crítica y marxista.

Las posturas más radicales en el trabajo social se manifiestan en lo que Netto (2012) denominó para el caso brasilero como Intensión de Ruptura. En el plano latinoamericano, los principales exponentes de la renovación crítica son las experiencias de la Universidad Católica de Valparaíso, el Método BH en Brasil y el Método Caldas en Colombia ${ }^{19}$.

\footnotetext{
${ }^{18}$ Aunque el texto de Netto (2012) se refiere a la experiencia brasilera, también es posible identificar elementos de carácter latinoamericano.

${ }^{19}$ Para un análisis introductorio sobre el “Método Caldas”, ver Quintero (2014).
} 
Mientras que en el marco de la lucha de clases durante los años 1960 y 1970 se fortalecieron planteamientos emancipadores que se sumaban a la crisis del capital, en el movimiento reconceptualizador se constituyó un sector más radical que sustentado en el marxismo (fundamentalmente de corte maoísta, althusseriano y cristiano), pretendió superar el carácter reproductor de la profesión, procurando inscribirla en las luchas 'revolucionarias'. El contexto revolucionario latinoamericano que determina la profesión, traducido sin mediaciones al movimiento de la Reconceptualización, hizo que se presentaran fuertes límites de orden 'voluntarista', 'politicista' y 'mesiánico', evidentes en las pretensiones profesionales de "agentes de cambio" y "transformación social”"20.

Es claro que los impactos de la Reconceptualización se deben identificar en los contextos particulares en los que se desarrollaron, es decir, que la evaluación debe ser una tarea de investigadores de cada país; sin embargo, al reconocer los trazos más amplios del movimiento, es posible identificar algunas características que bien podemos presentar como consecuencias generales del proceso latinoamericano ${ }^{21}$.

- La necesidad de superar la intervención técnica y caritativa exigía la incorporación o creación de nuevos instrumentos de intervención a través de los cuales se pudiera realizar un atendimiento más eficaz de los "problemas sociales".

- Ante los límites propios de intervenciones filantrópicas y caritativas, se recurre a la incorporación de la investigación como elemento indispensable para la producción de conocimientos, cualificando del ejercicio profesional.

- El estudio de las relaciones sociales arroja como premisa fundamental el reconocimiento de las contradicciones sociopolíticas y económicas como condiciones fundamentalmente sociocolectivas (interpretadas en algunos casos como lucha de clases), lo que lleva a cuestionar la sobrevaloración de los individuos y la psicologización de la cuestión social.

- Como consecuencia del enfrentamiento entre perspectivas académico-políticas, se genera una pluralidad significativa en los referenciales teóricos-metodológicos, donde se incorporan al debate nuevos fundamentos de las ciencias sociales y el marxismo.

- La creación o incorporación de nuevos fundamentos teórico-políticos brindan la posibilidad de reconocer las particularidades de las relaciones sociales del contexto latinoamericano, reevaluando contextos que históricamente se habían presentado como únicos posibles y deseables.

\footnotetext{
${ }^{20}$ A modo de análisis retrospectivo Lima (1979) presenta algunas ideas fundamentales; también en Quiroga (2000, 1990), se encuentran importantes reflexiones.

${ }^{21}$ Son diversos los autores que desde posiciones teórico-políticas distantes han realizado sistematizaciones sobre los aportes y límites de la Reconceptualización; para conocer algunas tendencias, ver un primer balance en Alayón: 1975, al igual que una compilación amplia y variada de Alayón: 2005. En la edición $N^{\circ} 40$ de la revista Em Pauta (2017) son publicados varios artículos que hacen análisis retrospectivos sobre la Reconceptualización en diferentes países.
} 
- La creación de asociaciones, federaciones, centros de estudio y demás instituciones de orden nacional y latinoamericano posibilitan un debate amplio, plural y permanente sobre la profesión y la sociedad.

- La creación de revistas y la publicación de libros encargados de difundir la producción de conocimiento sirve como herramienta estimulante del debate y articulación al interior de la profesión, y de ésta con las ciencias sociales.

- El debate plural y más cualificado a través de seminarios, congresos y demás actividades potencializa el desarrollo profesional en toda la región y la interlocución con los actores del contexto sociopolítico.

\section{Algunas consideraciones finales}

El modo de producción capitalista está constituido por elementos eminentemente contradictorios de orden político y económico que de manera permanente posibilitan su reproducción y negación. Durante los años 1960 y 1970 tales contradicciones se constituyen en crisis estructural que genera diversas transformaciones. El enfrentamiento político de fuerzas antagónicas agudiza las contradicciones del capital (como relación social) y genera impactos directos en instituciones privadas y públicas como las universidades, donde se presentan diferentes perspectivas teórico-políticas.

Las crisis (siendo parte constitutiva del capital) representan situaciones concretas en las que es posible dar continuidad al statu quo, generar algunas reformas, o impulsar procesos de ruptura radical. De este modo, se debe entender que los periodos de crisis brindan las posibilidades para la transformación social y renovación profesional; no obstante, la materialización de estas posibilidades depende de la praxis de las organizaciones sociales y profesionales inscritas en las luchas concretas, lo que niega cualquier relación mecánica (causa y efecto) entre transformación social y profesional.

La temporalidad de la Reconceptualización (décadas 1960-1970) coincide con la crisis del capital, y fundamentalmente con el fortalecimiento de las contiendas políticas protagonizadas por fuerzas cuestionadoras al orden hegemónico, lo que permite indagar las mediaciones entre condiciones sociohistóricas y la dinámica particular de la profesión. La crisis del trabajo social tradicional y su necesaria renovación no es otra cosa que una expresión profesional de la crisis de la renovación y crisis capitalista que transita de un ciclo expansivo hacia una crisis estructural.

En el caso del trabajo social, como profesión inscrita en la división sociotécnica del trabajo, durante estas décadas se genera una renovación que trae por lo menos tres tendencias teóricopolíticas, caracterizadas por la defensa al tradicionalismo profesional, la modernización de corte desarrollista y la intención de ruptura inspirada en el marxismo ${ }^{22}$.

${ }^{22}$ Como fue mencionado anteriormente, esta línea interpretativa es sugerida por Netto (2012). 
En términos generales, con la renovación se introduce en la profesión el pensamiento científico positivista (con sus formas de intervención) y el marxismo (con diversas corrientes); esta nueva condición abre un ciclo de tensiones y contradicciones que disputan la hegemonía en la dirección de la formación y el ejercicio profesional.

A pesar de los aportes ya mencionados, gracias a los cuales el trabajo social logra dar significativos saltos cualitativos, la crítica marxista desarrollada durante la Reconceptualización, al ser una crítica con un fuerte carácter 'politicista', que corresponde al contexto en que se encuentra inmersa, presentó límites teóricos y políticos que sólo se resuelven con un análisis radical (ir a la raíz) de la producción y reproducción social, para lo cual la obra madura de Marx (crítica de la economía política) es pieza fundamental.

Este trabajo tan solo es una forma introductoria de presentar el contexto, tendencias y actores de la Reconceptualización del trabajo social; su carácter introductorio muestra un amplio panorama que debe ser decantado con análisis más específicos. Si con esta reflexión se logra identificar el ingreso del pensamiento crítico y el marxismo a la profesión como una relación dialéctica entre sociedad y profesión, nuevos interrogantes deberán ser planteados para afinar la comprensión de la historia.

Una de las preguntas que debe guiar nuevas reflexiones e investigaciones es ¿Qué tipo de marxismo caracteriza la Reconceptualización? El intento por responder a este interrogante no puede sustentarse en análisis fragmentados (sean políticos, económicos o culturales), sino que deben responder a la perspectiva de totalidad, donde se establecen claras relaciones entre el momento ontológicamente predominantes y las múltiples determinaciones ${ }^{23}$.

\section{Referencias}

Ander-Egg, E. y Kruse, H. (1984). Del paternalismo a la conciencia de cambio. Buenos Aires, Argentina: Ecro.

Ander-Egg, E., Cassineri, E., Fernández, L., Parisi, E. y Barreix, J. (1975). Del ajuste a la transformación: apuntes para una historia del Trabajo Social. Buenos Aires, Argentina: Ecro.

Gough, I. (1982). Economía Política del Estado del Bienestar. Madrid, España: Blume Ediciones.

Harvey, D. (2013). O novo imperialismo. São Paulo, Brasil: Edições Loyola.

\footnotetext{
${ }^{23}$ En la Revista Serviço Social \& Sociedade, 133, se publicó un artículo que presenta una evaluación sobre las características del marxismo incorporado en la Reconceptualización.
} 
Contexto, tendencias y actores de la Reconceptualización

Iamamoto, M. y Carvalho, R. (1984). Relaciones sociales y Trabajo Social. Lima, Perú: Editorial Alfa S.A.

Iamamoto, M. (2003). El servicio social en la contemporaneidad. Trabajo y formación profesional. São Paulo, Brasil: Cortez Editora.

Lima, L. (1979). Marchas y contramarchas delTrabajo Social: repasando la Reconceptualización. Revista Acción Crítica, 6, 25-31.

Mandel, E. (1985). O Capitalismo Tardio. São Paulo, Brasil: Nova Cultura.

Manrique, M. (1982). De apóstoles a agentes de cambio. El Trabajo Social en la historia latinoamericana. Lima, Perú: CELATS.

Mèszáros, I. (2013). A crise estrutural do capital. São Paulo, Brasil: Editorial Boitempo.

Mojica, J. y Quiroga, C. (1975). Centro Latinoamericano de Trabajo Social. Recuperado de http: / / www.ts.ucr.ac.cr/binarios/pela/pl-000111.pdf

Navarro, V. (1997). Neoliberalismo y Estado del Bienestar. Barcelona, España: Editora Ariel.

Netto, J.P. (2012). Ditadura e Serviço Social. Uma análise do Serviço Social no Brasil pós-64. São Paulo, Brasil: Cortez Editora.

Quintero, S. (2014). El “Método Caldas” y la Reconceptualización del Trabajo Social. Revista Eleuthera, 10, 182-203.

Quintero, S. (2018). El marxismo en la Reconceptualización: ¿De qué marxismo se trata?. Servicio social y sociedad, 133, 566-584.

Quiroga, C. (2000). Invasión positivista en el marxismo: el caso de la enseñanza de la metodología en el Servicio Social. São Paulo, Brasil: Cortez Editora.

Quiroga, C. (1990). Una invasión invisible. Reducciones positivistas en el marxismo y sus manifestaciones en la enseñanza metodológica en el Servicio Social. Parte I. Revista Acción crítica, 27, 64-110.

Sader, E. (1992). Cuba, Chile, Nicarágua. Socialismo na América Latina. São Paulo, Brasil: Atual. 